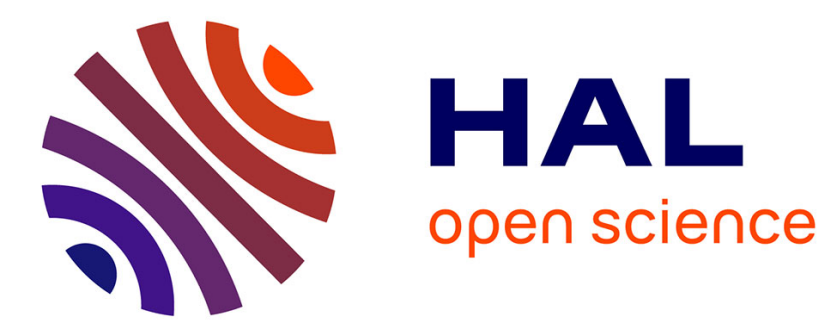

\title{
Supply chain business patterns definition for process interoperability
}

Esma Yahia, Michel Bigand, Jean Pierre Bourey, Emmanuel Castelain

\section{To cite this version:}

Esma Yahia, Michel Bigand, Jean Pierre Bourey, Emmanuel Castelain. Supply chain business patterns definition for process interoperability. 13th IFAC Symposium on Information Control Problems in Manufacturing, INCOM'2009, Jun 2009, Moscou, Russia. pp.CDROM. hal-00403789

\section{HAL Id: hal-00403789 \\ https://hal.science/hal-00403789}

Submitted on 13 Jul 2009

HAL is a multi-disciplinary open access archive for the deposit and dissemination of scientific research documents, whether they are published or not. The documents may come from teaching and research institutions in France or abroad, or from public or private research centers.
L'archive ouverte pluridisciplinaire HAL, est destinée au dépôt et à la diffusion de documents scientifiques de niveau recherche, publiés ou non, émanant des établissements d'enseignement et de recherche français ou étrangers, des laboratoires publics ou privés. 


\title{
Supply chain business patterns definition for process interoperability
}

\author{
Esma Yahia*, Michel Bigand**, Jean-Pierre Bourey**, Emmanuel Castelain** \\ *Centre de Recherche en Automatique de Nancy (CRAN - UMR 7039), Nancy-University, CNRS, France (e-mail: \\ esma.yahia@cran.uhp-nancy.fr). \\ **Ecole Centrale de Lille, Industrial Engineering Laboratory of Lille, FRANCE (e-mails: \\ michel.bigand@ec-lille.fr, jean-pierre.bourey@ec-lille.fr,emmanuel.castelain@ec-lille.fr)
}

\begin{abstract}
In the framework of international trading, new regulations are being drawn up concerning safety and in order to prohibit counterfeit goods. Due to the short delays imposed by Customs, the trend is still toward paperless trading. As a consequence, a better process and software interoperability is needed between the different actors of trading (customer, supplier, Customs...); a first step in software interoperability consists in process modeling. This paper presents a pragmatic guideline to generating successfully the business process model. The original aspects are first to use BPMN (Business Process Modeling Notation) for the representation of all types of flows (and not only information flows), and second to propose BPMN business patterns for the international trading purpose.
\end{abstract}

Keywords: BPMN, business pattern, Model Driven Architecture, Model Driven Engineering, Model Driven Interoperability.

\section{INTRODUCTION}

An increase in international trading has led to an improvement in information exchanges between the different actors - customer, importer, supplier, Customs administration. The economic issue is very important for them. For example, the time lost during container transport due to waiting for documents generates capital cost. In addition, Customs play an important role in national economy: if it is able to ease administrative procedures for companies, these companies will remain domiciled in the country concerned; otherwise companies will choose another country. This is significant since some of the taxes collected come back to the country where the firm is domiciled.

Another aspect is the evolution of the Customs regulations in order to ensure safety of exchanges and to fight against terrorism, and also to avoid counterfeiting. For example, new procedures for communication between administrations (Export Control System and Import Control System) will be effective on $1^{\text {st }}$ July 2009 in Europe.

For these reasons, the trend is still toward paperless trading. So, interoperability problems appear between the information systems of the different actors. A model driven approach beginning with company modelling is recommended (Grangel et al. (2006)); this approach is based on MDA (Model Driven Architecture) (OMG (2003)), a development process that is based on several levels (Fig. 1): CIM (Computation Independent Model) that models an organization, PIM (Platform Independent Model) that models the subset of the organization that will be concerned by the software development, and the PSM (Platform Specific Model) that takes into account the specificities of the development environment. The last level is the ESA (Enterprise Software Application). The logic of MDA is to allow automatic model transformations between the PIM and
PSM levels and also between PSM and ESA levels. A model at CIM level can give several PSM models, depending on the target platform, and bridges can be built between elements of the different PSM models. A method called Model Driven Interoperability (MDI) (Grangel et al. (2006)) based on MDA process has been proposed by INTEROP NoE (INTEROP (2007)), and more precisely by Task Group 2 (TG2), in order to search for solutions to achieve interoperability following a model-driven approach.

This paper focuses on process modelling at CIM level. Part 2 describes a short state of the art of architectures, methods and formalisms in the domain of enterprise modelling. In part 3, a pragmatic guideline to generate successfully the business process model with BPMN (OMG (2009)) is presented, taking into account all types of flows (information, documents, physical flows, financial flows) spread between the different stakeholders of trading; this guideline uses business pattern designed specifically for international trading purposes. An example illustrating the exchange between the Customs office and one of its partners is presented in part 4 and finally part 5 concludes and gives some perspectives related to future works.

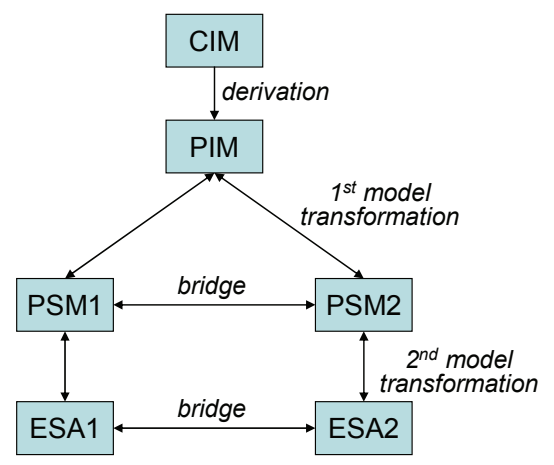

Fig. 1. MDA process in 4 levels 


\section{STATE OF THE ART ON COMPANY MODELLING}

Company modelling can be considered as a prerequisite to achieve integration; it can also help to solve interoperability problems starting from a higher level of abstraction than code. Vernadat (1996) defines it as the art of externalising company knowledge and know-how, which represents the company in terms of its organisation and functions (activities, information, resources and organisation units, and system infrastructure and architecture).

The objective is first to make a rough picture of the existing organisation ("as-is" model) and then to propose evolutions ("to-be" model) to optimise performance of the organisation. Several "to-be" models can be compared, possibly by using simulation tools. Then, the way to go from the "as-is" to the "to-be" organisation has to be prepared, taking into account the problem of change management.

Company modelling is also the process of drawing up models of the whole or part of the company that depict its different functions. It is achieved by using Enterprise Modelling Languages (EML). In this context, several architectures deal with Enterprise Modelling, such as GRAI (Doumeingts et al. (1993); Berio et al. (2003)), CIMOSA (Berio and Vernadat (1999), PERA (Williams (1993)), UMM (UN/CEFACT's Modeling Methodology) (UN/CEFACT (2003)) that enables the business modeler to capture the business knowledge independent of the underlying implementation technology like Web Services or ebXML (Hofreiter et al (2006); Liegl et al (2006)) and so forth.

These architectures are often proposed with a method that can be applied in order to produce company models. For example, GRAI gives recommended types of planning, organisation and steps; it contain also some heuristics for existing situation analysis.

Finally, these methods use formalisms that can be specific (GRAI for example introduces "GRAI-grid", "extended actigram"...), or generic. In this last category, we can name for example IDEF (IDEF (2007)), UML® (OMG (2008)) and BPMN.

These last two formalisms are proposed by Object Management Group (OMG) that provides good guidelines; so it cannot be ignored.

$\mathrm{UML} \circledast$ is basically more software-oriented, but extension mechanisms are proposed that allow the enrichment of the meta-model. Thus, it is possible to create stereotypes, for example, that are totally understandable by a layman without computer science culture. It is probably the best solution, because in the following transformations toward PIM and PSM levels, UML ${ }^{\circledR}$ will often be used for software development.

But, in practice, a lot of reluctance about UML $\AA$ can be noticed among non-specialists who are today attracted by BPMN. That is surprising because, for example, an UML $\AA$ activity diagram seems more understandable than a BPMN diagram; the reasons for such an attitude, due to a lack of training and sometimes difficulties in abstraction and modelling capacities, will not be studied in this paper. That reality must be taken into account, and BPMN is here chosen at CIM level, even if that will need a subsequent transformation in $U M L \AA$, which is not detailed in this paper.

The main goal of BPMN is to provide a standard notation that is easily understandable by all business stakeholders and thus independently of the tool used. The basic elements of representation of BPMN are the following:

- Flow Objects: Events, Activities, Gateways,

- Connecting Objects: Sequence Flow, Message Flow, Association,

- Swimlanes: Pool, Lane,

- Artifacts: Data Objects, Group, Annotation.

One can notice that a large number of icons are proposed in BPMN that are sometimes sophisticated; in reality, only a subset of these icons is currently used.

Conforming to the OMG's specifications in terms of BPMN representation, many tools can be used for model processes. In our work, TIBCO Business Studio $^{1}$ was selected. This Eclipse-based software program makes it possible to add plug-ins for processing model transformations using transformation languages like ATL (Jouault (2006)).

\section{GUIDELINE FOR BUSINESS PROCESS MODEL WITH BPMN}

\subsection{Flows to be modelled}

Modeling a business process consists in defining a set of coordinated tasks or activities, all conducted by people and/or equipment in order to accomplish some desired end-result identified by the company.

Usually, the flows modelled with BPMN are essentially information and documentary flows, which is a pity. To overcome this lack, this proposition aims to represent other flows (physical flows: goods, material, equipment..., financial flows) clearly on the BPMN diagrams. The proposition is to use BPMN as the main and, perhaps, unique model at CIM level for quality management, production management, computerization...

In the case of a logistic chain, we have identified four flows which are:

- The physical flows that correspond in practice to the flows of products going from the upstream of the logistic chain until its approval,

- The information flows that encompass all the information exchanged between the actors of the studied system,

- The financial flows that correspond to the fund transfers by means of checks or cash,

- The documentary flows that are all the documents exchanged between the actors of the studied system.

Since BPMN has rich graphical elements, it offers several possibilities to represent those flows. The major difficulty lies in the choice of the best alternatives to have

\footnotetext{
${ }^{1}$ http://www.tibco.com/devnet/business_studio/default.jsp
} 
understandable models. If one considers two activities in a process that are related to goods moving, the physical flow can be represented using a data object that mentions the type of goods and quantity.

For the documentary and financial flows, the use of a data object is sufficient insofar as it offers the possibility of indicating if this flow is compulsory or not for the start of the activity.

Concerning the informational flows, one can use either the "event" to represent the flow at the entry of a given process or the data object for intermediate information. When using an event, the activity will wait for the information to reach it before starting. This is not the case for all the intermediate activities, which is also why the data object has been chosen.

In order to make the representation more readable, a differentiation is proposed between physical, informational, documentary and financial flows by the mean of a specific colour and also a prefix (for monochrome diagrams) (Fig. 2).

\begin{tabular}{|l|l|l|c|}
\hline \multicolumn{3}{|c|}{ Representation Colour } & Prefix \\
\hline Physical flows & Data Object & Red & PF \\
\hline Information flows & Data Object/event & Green & IF \\
\hline Documentary flows & Data Object & Brown & DF \\
\hline Financial flows & Data Object & Pink & FF \\
\hline
\end{tabular}

Fig. 2. Differentiation of BPMN flows types by colour and prefix

These different types of flows are represented on an example of a BPMN diagram in Fig. 3.

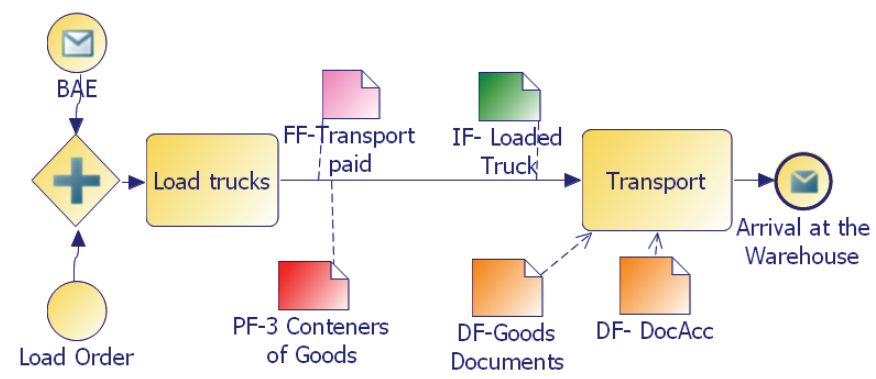

Fig. 3. Example of BPMN diagram with different types of flows

The process corresponds to the transport of goods from the quayside to the warehouse where goods will be stocked. For this, two main activities were identified: the first is the activity of loading the trucks and it starts once the message containing the BAE and the load order has arrived. The second activity is the transport and it is completed when trucks arrive at the warehouse.

Different flows appear in this process; the physical flow indicates for example the quantity of goods transported, while the financial flow "Transport paid" and the information flow "Loaded Truck" indicate that the action of transport cannot start before they have been completed. Two other flow-type documents are connected directly to the activity of transport; these documents must accompany the goods and could be demanded when there is a Customs' check.

\subsection{Steps of the modelling}

The main steps proposed to achieve the "as-is" process at CIM level are the following:

Step 1: This consists in interviewing the stakeholders in the company in order to identify the main offered services and products, the organization (human resources, hierarchy, roles), the different processes, the customer types, the means to exchange the information, the various actors' functions and the circuit of decision-making.

Step 2: Once the information has been collected, a report is drafted that will be afterwards validated by the stakeholders of the company.

Step 3: The aim of this step is to give a first synthetic and global vision to better understand the flows without entering into the detail of who emits and receives them. The output of this step is a table (with a non-standard formalism) containing the four previous categories of flows that are represented in lines and the schedule of the goods moving in columns (Fig. 4).

\begin{tabular}{|c|c|c|c|}
\hline \multicolumn{4}{|c|}{ Flow analysis } \\
\hline & Phase 1 & Phase 2 & Phase 3 \\
\hline 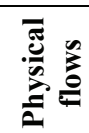 & & & \\
\hline 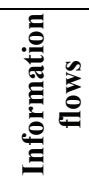 & & & \\
\hline 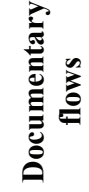 & & & \\
\hline 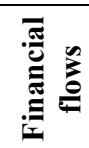 & & & \\
\hline
\end{tabular}

Fig. 4. Table-type for the first global representation of the flows

Step 4: This is a translation in BPMN formalism. At this level, the pools will correspond to the internal and external actors of the company. In each pool, lanes will be identified that correspond to the organizational units which are mostly roles or internal departments 


\subsection{Supply chain business patterns}

Several workflow patterns exist (like basic control flows, branching patterns, structural patterns, multi instances patterns, state based patterns, cancellation patterns..., see for example DiveIntoBPM (2008)), that constitute practical rules for the correct use of BPMN.

The purpose here is different: in the supply chain domain, many organisations and flows are similar. It is thus interesting to build generic models once that can be adapted to particular problems.

A business pattern is a generic description of a business organization part used to produce solutions related to the business itself. Several business patterns have been proposed, for example for "payment expenses" (Fig. 5), which is described hereafter corresponding to the formalism of representation recommended in this reference (Ambler (1998))

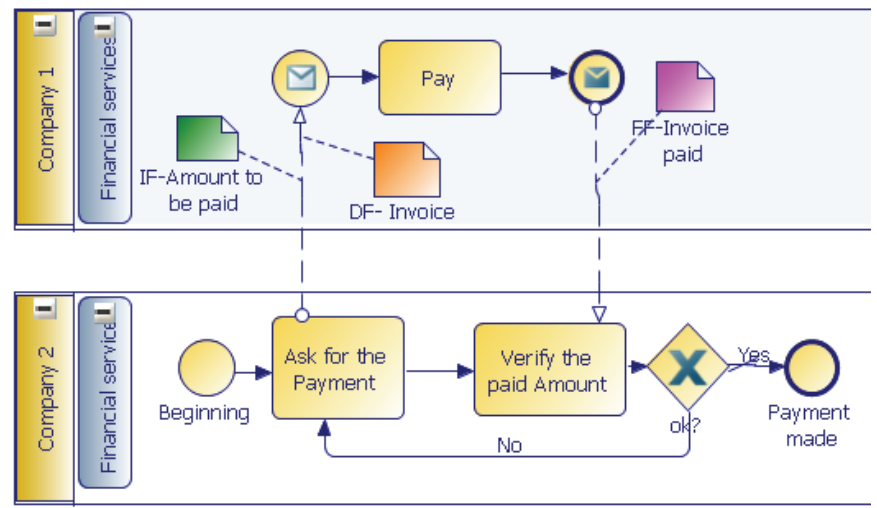

Fig. 5. Proposed business pattern "payment expenses"

Name: Payment expenses pattern

Target: The pattern of "payment of expenses" aims to describe the procedure of payment of diverse types of expenses.

Initial context: The pattern can be used in the various cases of expenses payments in the framework of an activity concerning logistics. It can be related to the transportation, storage, Customs declaration, Customs clearance...

Solution: The process begins when Company 2 sends the invoice and asks Company 1 for the payment and indicates the amount of its services that can correspond, in our case, to transportation, storage, Customs declaration...

The financial office of Company 1 proceeds to the payment and sends the paid invoice. A verification of the amount paid is carried out by the financial service of Company 2. Once the amount matches what was requested, the process is finished. Otherwise, the financial service will notify and ask for the payment a second time.

Resulting context: This pattern facilitates the modelling of the expenses payment.

Connected patterns: In our case, this pattern is not related to another pattern.

\section{CASE STUDY}

This case study was carried out in the framework of the ASICOM (a French acronym for "Interoperable Information System Architecture for Trade Industry") project and with some of its partners. The exchanges between a commercial company and Customs have to be modelled, and several case studies exist depending on the types of goods, the transportation...

The case study concerns a French commercial company importing textile goods from China, storing these goods in its warehouse under a specific Customs system allowing it to postpone the payment of taxes and finally dispatching these goods to its own stores.

After several meetings with the heads of the Customs department in this company, a scenario representing the most frequent cases was chosen, in order to provide a global understanding of the complete supply chain. Once this scenario had been validated, the flows began to be identified with the help of the table as shown in step 3.

In the BPMN model obtained in step 4 (Fig. 6), the pools correspond to the actors of the project who are: the company, the shipping company, the Customs declarer, the service of the Customs. In each pool, the lanes are represented as follows: for the shipping company the carrier and the warehouseman are introduced and for the company, the carrier, the approved economic actor, the administration and the warehouseman are created. In the pool of the Customs declarer one lane corresponds to the declarer. Finally, two lanes are identified for the pool of Customs: the Customs office at the entrance and the local Customs office.

According to the fixed perimeter, the business process begins at the exit of the goods from the Shanghai harbor and finishes at the arrival in the store where goods are going to be sold.

Some similar activities were identified when modeling the business process; for example the payment of expenses explained previously. In fact, it occurs the first time when paying the maritime transport costs and a second time when paying the Customs taxes. The generic business pattern called "payment expenses" has been used to suit the different payments made.

Supported with the guideline detailed in this paper, the modeling of a business process has been completed. Once this "as-is" model, in Fig. 6, is validated by all the stakeholders of the company, it will be used to establish the "to-be" model (not detailed in this paper) by performing all the necessary modifications. After all, the "to-be" CIM can be derived to obtain the "to-be" PIM as indicated in Fig.1. 


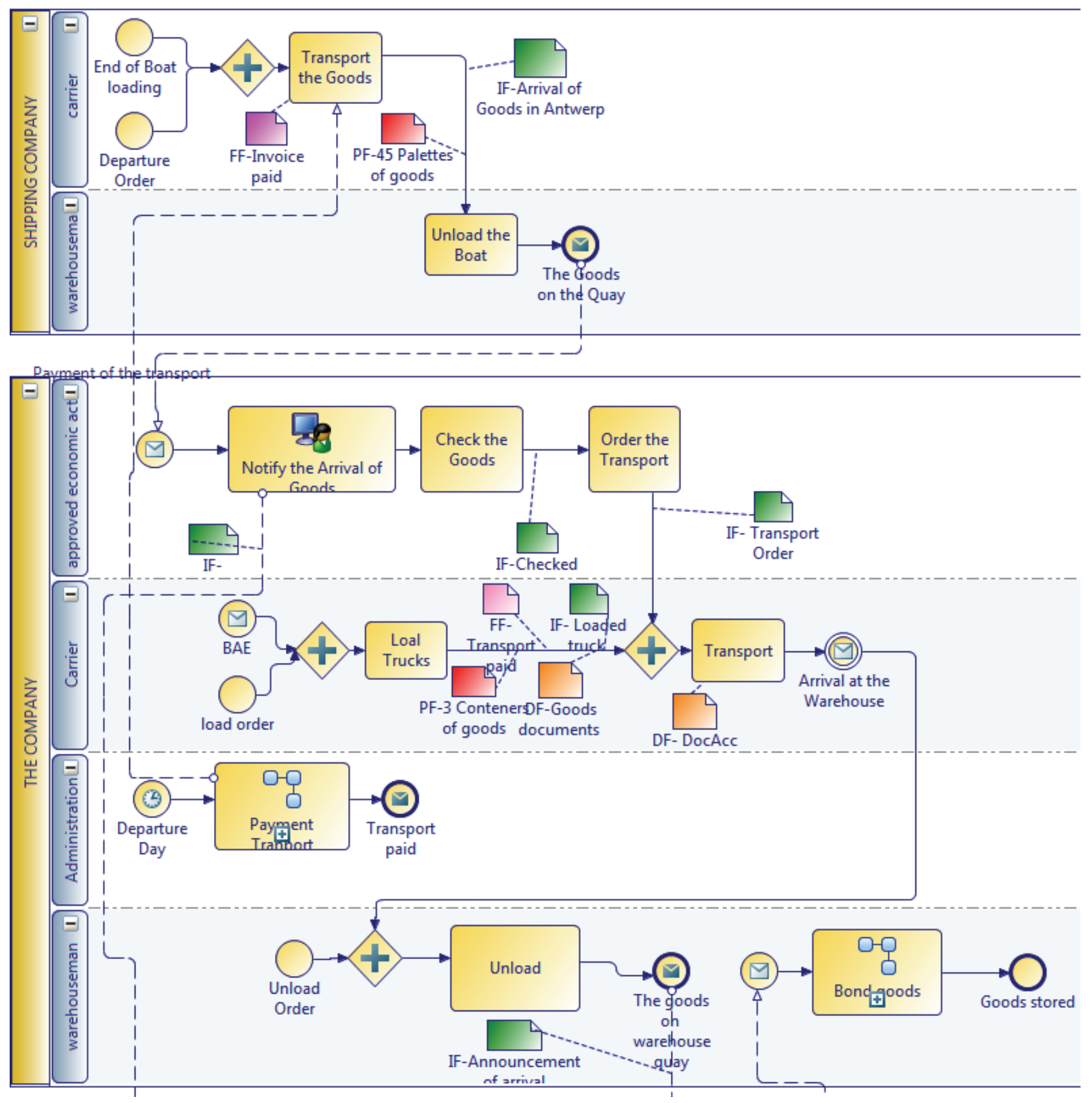

Fig. 6. Excerpt of the whole process modeled in the framework of the case study

\section{CONCLUSIONS}

The first step in the Model Driven Interoperability method consists in company modelling, at Computation Independent Model level.

This paper proposes the use of BPMN whose formalism is enriched in order to take into account all types of flows. In addition, business process patterns have been developed in the framework of the supply chain in international trading.

The knowledge given by this enriched BPMN formalism makes it possible to highlight the links between the process view and the other domain specific views (product, information, document ...). But, from this process view, all the manipulated flows are presented without any structure. The enrichment with ontologies and/or some UML ${ }^{\circledR}$ diagrams seems to be an interesting topic to be investigated in order to obtain a full description of the system at CIM level. This full description is needed for transforming the models at lower levels (PIM, PSM). The aim of these multiple model transformations is to generate code that can be used for example for Service Oriented Architecture (SOA) (Touzi (2007)). 


\section{ACKNOWLEGMENTS}

This work was carried out in the framework of the ASICOM project (a French acronym for "Interoperable Information System Architecture for Trade Industry") that obtained the label of "Pôle de Compétitivité Industries du Commerce Nord Pas de Calais, France".

\section{REFERENCES}

Ambler, S.W., (1998), Process Patterns building Large Scale Systems using Object technology, SIGS Books, Cambridge University Press. ISBN 0-521-64568-9.

Berio G., Panetto H., Petit M., Benali K., et al., (2003), D3.2: Core constructs, architecture and development strategy, UEML TN IST - 2001 - 34229.

DiveIntoBPM (2008), Business Process definitions and models, URL http://diveintobpm.org/.

Doumeingts, G., Chen, D., Vallespir, B., Fénié, P., and Marcotte, F. (1993). GIM (GRAI Integrated Methodology) and its Evolutions - a Methodology to Design and Specify Advanced Manufacturing Systems. In H. Yoshikawa and J. Goossenaerts (eds.), DIISM '93: Proceedings of the JSPE/IFIP TC5/WG5.3 Workshop on the Design of Information Infrastructure Systems for Manufacturing, volume B-14 of IFIP Transactions, 101120. North-Holland.

Grangel, R., Bourey, J.P., and Berre, A. (2006). Solving Problems in the Parametrisation of ERPs using a ModelDrivenApproach. In G. Doumeingts, J. Muller, G. Morel, and B. Vallespir (eds.), Enterprise Interoperability. New Challenges and Approaches, Interoperability for Enterprise Software and Applications Conference (IESA'06), 91-101. Springer. ISBN 978-1-84628-713-8.

Hofreiter, B., Huemer, C.,Liegl, P., Schuster, R., Zapletal, M. (2006). UN/CEFACT'S Modeling Methodology (UMM): A UML Profile for B2B e-CommerceB. Advances in Conceptual Modeling-Theory and Practice, ER 2006 Workshops BP-UML. Springer. 978-3-54047703-7

IDEF (2007). Integrated DEFinition Methods, URL http://www.idef.com/.

INTEROP (2007). Interoperability Research for Networked Enterprises Applicationsand Software NoE (IST-2003508011), URL http://www.interop-noe.org.

Jouault, F., Allilaire, F., Bézivin, J., Kurtev, I., and Valduriez, P. (2006). ATL: a QVT-like transformation language. In P.L. Tarr and W.R. Cook (eds.), OOPSLA Companion, 719-720. ACM.

Liegl, P., Schuster, R., Zapletal, M., (2006), A UML Profile and Add-In for UN/CEFACT's Modeling Methodology, $\mathrm{PhD}$ Thesis, Austria.

OMG (2003). MDA Guide Version 1.0.1. Object Management Group, document number: omg/2003-0601 edition. URL http://www.omg.org/mda.

OMG (2008), Unified Modeling Language: Superstructure and Infrastructure, version 2.1.2. Object Management Group, URL http://www.omg.org/technology/documents/ modeling_spec_catalog.htm\#UML.
OMG (2009), Business Process Management Notation, version 1.2. Object Management Group, URL http://www.omg.org/spec/BPMN/1.2.

Touzi, J., (2007), Assistance in the conception of Collaborative Information system supporting the companies' interoperability (In French "Aide à la conception de Système d'Information Collaboratif support de l'interopérabilité des entreprises"). PhD Thesis, Ecole des Mines d'Albi Carmaux, France.

UN/CEFACT (2003), United Nations Centre for Trade Facilitation and Electronic Business, UN/CEFACT Modeling Methodology (UMM), User Guide CEFACT/TMG/N093.

Vernadat, F.B. (1996). Enterprise Modeling and Integration: Principles and Applications. Chapman and Hall.

Williams, T.J. (1993). The Purdue Enterprise Reference Architecture. In Proceedings of the Workshop on Design of Information Infrastructure Systems for Manufacturing. Elsevier. URL http://www.ecn.purdue.edu/IIES/ PLAIC/EnterpriseHandbook_PERA.pdf. 